\title{
Differences in sorption behavior of the herbicide 4-chloro-2-methylphenoxyacetic acid on artificial soils as a function of soil pre-aging
}

\author{
Georg Waldner • Wolfgang Friesl-Hanl • Georg \\ Haberhauer • Martin H. Gerzabek
}

Received: 5 January 2012 / Accepted: 8 June 2012 /Published online: 3 July 2012

(C) The Author(s) 2012. This article is published with open access at Springerlink.com

\begin{abstract}
Purpose The sorption behavior of the herbicide 4-chloro-2methylphenoxyacetic acid (MCPA) to three different artificial soil mixtures was investigated. Artificial soils serve as model systems for improving understanding of sorption phenomena.

Materials and methods The soils consisted of quartz, ferrihydrite, illite, montmorillonite, and charcoal. In a previous study, several selected mixtures had been inoculated with organic matter, and microbial aging (incubation) had been performed for different periods of time (3, 12, and 18 months) before conducting the sorption experiments. The effect of this preincubation time on the sorption behavior was determined. Interaction of MCPA with soil surfaces was monitored by aqueous phase sorption experiments, using high-performance liquid chromatography/ultraviolet and in selected cases Fourier-transformed infrared spectroscopy.

Results and discussion The sorption behavior showed large differences between differently aged soils; Freundlich and linear sorption model fits (with sorption constants $K_{f}, 1 / n$ exponents, and $K_{d}$ values, respectively) were given for $\mathrm{pH}=3$ and the unbuffered $\mathrm{pH}$ of $\sim 7$. The largest extent of sorption from diluted solutions was found on the surfaces with a pre-incubation time of 3 months. Sorption increased at acidic $\mathrm{pH}$ values.
\end{abstract}

Responsible editor: Gabriele Schaumann

G. Waldner $(\bowtie) \cdot$ W. Friesl-Hanl

Health and Environment Department,

AIT Austrian Institute of Technology $\mathrm{GmbH}$,

Konrad-Lorenz-Strasse 24,

3430 Tulln, Austria

e-mail: georg.waldner@ait.ac.at

G. Haberhauer $\cdot$ M. H. Gerzabek

Institute of Soil Research,

University of Natural Resources and Life Sciences,

Peter-Jordan-Strasse 82,

1190 Vienna, Austria
Conclusions Regarding the influence of aging of artificial soils, the following conclusions were drawn: young artificial soils exhibit stronger sorption at lower concentrations, with a larger $K_{f}$ value than aged soils. A correlation with organic carbon content was not confirmed. Thus, the sorption characteristics of the soils are more influenced by the aging of the organic carbon than by the organic carbon content itself.

Keywords Artificial soils · FTIR · Incubation time · MCPA $\cdot$ Soil components $\cdot$ Sorption

\section{Introduction}

Transport, transformation, and fate of organic chemicals in soils and in the environment are topics of numerous investigations and reviews (Barrow 2008; Haberhauer et al. 2000; Barrow 1998; Calvet 1989). Retention may cause a reduced bioavailability but also increased problems with detoxification strategies; sorption of herbicides depends on various properties of soils and the substance itself. Soil properties depend on the one hand on the surface and structural characteristics of its inorganic components (minerals) like quartz (QU; Scheffer and Schachtschabel 2002), montmorillonite (MO; Li et al. 2003), illite (IL; Polubesova and Nir 1999), ferrihydrite (FH; Janney et al. 2000; Friesl-Hanl et al. 2009; Waldner et al. 2010; Klepsch et al. 2011), and on the other hand on the surface properties of organic matter-in our case charcoal $(\mathrm{CH}$; Rennert et al. 2008; Derylo-Marczewska et al. 2010), and manure (MA; Haberhauer et al. 2001; Sheng et al. 2001). In a previous study (Heister et al. 2012; Pronk et al. 2012), several selected mixtures had been inoculated with organic matter, and microbial aging (incubation) had been performed for different periods of time $(3,12$, and 18 months) before conducting the sorption experiments. The effect of this pre-incubation time on the sorption behavior was now investigated in the present study. 
Each component shows its own specific sorption behavior (Totsche et al. 2010), which may or may not dominate the overall behavior of the incubated mixture, depending on the mixing ratios and/or extent of soil-organic interactions. QU exhibits almost no surface reactivity. MO is an expandable 2:1 clay mineral with a huge surface (predominantly inner surface) and is negatively charged at $\mathrm{pH}$ values commonly occurring in most soils. IL is also negatively charged but offers no inner surface. FH shows a huge surface and is positively charged at neutral $\mathrm{pH}$ values. $\mathrm{CH}$ is recalcitrant organic matter with a huge surface dominated by functional groups like carboxyl and graphene-like polycyclic aromatic surface structures. MA is a typical soil amendment and fertilizer, maintaining soil organic matter levels and fostering microbial activity; the manure used in the preparation of the soil mixtures was autoclaved. Artificial soil mixtures are a means to enhance understanding of the behavior of complex soil matrices and their interaction with xenobiotics like pesticides or heavy metals. The preparation of the artificial soils employed in this investigation is described elsewhere (Pronk et al. 2012).

4-Chloro-2-methylphenoxy acetic acid (MCPA) is an acidic herbicide belonging to a larger class of phenoxy acetic acid herbicides, which are widely used in agriculture, controlling annual and perennial weeds in cereals, grassland, trees, and turf. These herbicides represent a potential risk for water sources as they are poorly biodegradable and quite mobile in aqueous systems because of their acidic carboxyl group. MCPA has been found in well water in some countries and is classified by the US EPA as a potential groundwater contaminant and systemic toxicant (US EPA 1984). Due to the acidic carboxyl group (Addorisio et al. 2010), phenoxy acetic herbicides are able to form relatively strong complexes with polar species or, in anionic form, they can be involved in the formation of strong complexes with cations present in the soil. Cho et al. (2006) showed enhanced sorption of MCPA on activated carbon and a higher sorption of the herbicide at $\mathrm{pH} 3.5$ and a decrease of sorption with increasing $\mathrm{pH}$ of the solution.

Still, the behavior of MCPA in soils needs further research, as it is a currently used herbicide and especially in order to understand the contribution of different soil components and their associations (i.e., newly formed soil organic matter, SOM, or humic acid-clay complexes) to MCPA sorption. However, due to the relatively simple chemical structure, MCPA is also a good model for sorption experiments. The specific aim of the present paper was to study the influence of different microbial aging periods of the artificial soil surfaces as well as of $\mathrm{pH}$ on sorption of MCPA as well as to check the applicability of sorption study concepts to previous studies with real soils. The novelty of this study is based on the specific properties of the artificial soils and the changes in sorption characteristic as a result of SOM formation and/or formation of humic acidclay complexes.

\section{Materials and methods}

Chemicals Technical grade (97\%) MCPA was used as model substance. Its solubility in water at $25^{\circ} \mathrm{C}$ is $825 \mathrm{mg} \mathrm{L}^{-1}$ and its acidity constant $\left(\mathrm{pK}_{a}\right)$ is 3.07 . The agronomic dose of MCPA is between 1 and $2.5 \mathrm{~kg} \mathrm{ha}^{-1}$.

Artificial soils were produced at TU Munich (Heister et al. 2012; Pronk et al. 2012) to obtain simple model soils of known composition and better-defined interfaces. These soils consisted of varying mixtures of $\mathrm{QU}, \mathrm{FH}, \mathrm{CH}$, and IL. The mixtures had been amended with organic material (manure, MA) and inoculated with a soil microbial community for a certain time $(3,12$, and 18 months, in the following labeled as $3 \mathrm{M}, 12 \mathrm{M}$, and $18 \mathrm{M}$ ). The soils contained $42 \%$ sand, $52 \%$ silt, and $6 \%$ of particles $<6.3 \mu \mathrm{m}$ of varying composition of aforementioned components. Further properties are reported in Table 1.

Specific surface area (SSA) was measured by $\mathrm{N}_{2}$ sorption (BET isotherm). Soil C consisted of QU, FH, and MA; soil E was based on QU, MO, CH, MA, and soil $\mathrm{H}$ on QU, IL, $\mathrm{FH}, \mathrm{CH}$, and MA.

Experimental design Sorption isotherms were measured as follows: $6 \mathrm{~g}$ of each artificial soil sample was weighed into $30 \mathrm{~mL}$ centrifuge tubes made of glass. Six milliliters of $0.01 \mathrm{M}$ $\mathrm{CaCl}_{2}$ aqueous solutions of MCPA containing initial pesticide concentrations ranging between 0.1 and $300 \mathrm{mg} \mathrm{L}^{-1}$ was added to each vessel. The flasks were shaken for $24 \mathrm{~h}$. Preliminary kinetic experiments had demonstrated that sorption equilibrium was reached within less than $24 \mathrm{~h}$. Before conducting the present sorption experiments, the soils had not been sterilized, i.e., microbial degradation was not excluded; it can only be neglected within the first $24 \mathrm{~h}$ comparing the duration of these experiments with typical half-lives under similar conditions ( 13 days; Smith 1982). A 0.01 M solution of $\mathrm{CaCl}_{2}$ was used to ease phase separation and to keep ionic strength similar to natural soil solutions. The experiments were carried out at $20^{\circ} \mathrm{C}$. After centrifuging, the supernatant equilibrium solution was removed and the concentrations of MCPA in this supernatant solution, $C_{\text {eq }}$, were determined by high-performance liquid chromatography with an ultraviolet detector (Agilent 1100 series). As mobile phase, a mixture of $70 \%$ methanol, $29.7 \% \mathrm{H}_{2} \mathrm{O}$, and $0.3 \%$ acetic acid was used (isocratic elution). The analysis was done on a Supelco Discovery HS $\mathrm{C} 18$ column $(5 \mu \mathrm{m})$ at $25{ }^{\circ} \mathrm{C}$ and a flow of $1 \mathrm{~mL} \mathrm{~min}{ }^{-1}$. The MCPA was determined at the wavelength of maximum absorption (282 and $228 \mathrm{~nm}$ at the lowest concentrations). The MCPA adsorbed, $C_{s}$, was calculated from 
Table 1 Properties of artificial soil mixtures

\begin{tabular}{|c|c|c|c|c|c|c|c|c|c|c|}
\hline \multirow[b]{2}{*}{ Soil } & \multirow[b]{2}{*}{$\begin{array}{l}\text { Mineral } \\
\text { composition }\end{array}$} & \multirow{2}{*}{$\begin{array}{l}\mathrm{pH} \\
\text { All incubation } \\
\text { times }\end{array}$} & \multirow[t]{2}{*}{ pzc } & \multirow{2}{*}{$\begin{array}{l}\mathrm{SSA} \\
\mathrm{bulk} / \mathrm{m}^{2} / \mathrm{g} \\
t=0\end{array}$} & \multirow{2}{*}{$\begin{array}{l}\text { SSA } \\
(<20 \mu \mathrm{m}) / \mathrm{m}^{2} / \mathrm{g} \\
3 \mathrm{M}\end{array}$} & \multirow{2}{*}{$\begin{array}{l}\mathrm{Fe} \_\mathrm{d} / \mathrm{mg} / \mathrm{g} \\
\text { All incubation } \\
\text { times }\end{array}$} & \multirow{2}{*}{$\begin{array}{l}\text { Fe_o / mg/g } \\
\text { All incubation } \\
\text { times }\end{array}$} & \multicolumn{3}{|c|}{$\mathrm{C}_{\text {org }} / \mathrm{mg} / \mathrm{g}$} \\
\hline & & & & & & & & $3 \mathrm{M}$ & $12 \mathrm{M}$ & $18 \mathrm{M}$ \\
\hline $\mathrm{C}$ & $\mathrm{QU}, \mathrm{FH}, \mathrm{MA}$ & $6.8-7.7$ & & 2.7 & 6.8 & $5-6$ & $0.7-0.9$ & 16 & 15 & 13 \\
\hline $\mathrm{E}$ & $\mathrm{QU}, \mathrm{MO}, \mathrm{CH}, \mathrm{MA}$ & $6.9-7.6$ & & 2.5 & 7.3 & - & - & 30 & 28 & 26 \\
\hline $\mathrm{H}$ & QU, IL, FH, CH, MA & $7-7.6$ & & 3.4 & 6.7 & 6 & $0.8-1.0$ & 31 & 28 & - \\
\hline \multirow{4}{*}{$\begin{array}{l}\text { Individual } \\
\text { components }\end{array}$} & MO & & 8.2 & 28.8 & & & & & & \\
\hline & IL & & 8.3 & 12.3 & & & & & & \\
\hline & $\mathrm{CH}$ & & & 11.1 & & & & & & \\
\hline & FH & & 7.9 & $200-400$ & & & & & & \\
\hline
\end{tabular}

Soil data from Pronk (personal communication, 2010) and Pronk et al. (2012); BET data of components, own measurements; BET of FH (six lines) and pzc, literature data (Cornell and Schwertmann 1996)

$S S A$ specific surface area of two fractions, bulk soil vs. fraction $<20 \mu \mathrm{m} ; C_{\text {org }}$ organic carbon content; $F e \_d$ dithionite-extractable fraction (total iron content); $\mathrm{Fe} \_o$ oxalate-extractable fraction (poorly crystalline iron oxides); $3 M$ etc. incubation time (months)

the difference between the initial and final concentration of the $\mathrm{CaCl}_{2}$ solution. Blanks containing no MCPA were included, and flasks containing only MCPA and no soil were analyzed to determine adsorption on the surface of the flasks. All sorption experiments were done at least in duplicate. The unbuffered and unadjusted natural $\mathrm{pH}$ was $\sim 7$; additionally, in selected cases, $\mathrm{HCl}$ was added to adjust the $\mathrm{pH}$ to $\sim 3$ (not checked after equilibration).

Fourier transform infrared spectra (FTIR) were recorded in transmission mode with a Perkin Elmer Spectrophotometer (System 2000) over a range of 4,000-400 $\mathrm{cm}^{-1}$. For spectroscopic characterization, $1 \mathrm{mg}$ of sample were thoroughly mixed with $300 \mathrm{mg} \mathrm{KBr}$ (FTIR grade) and pressed to a pellet.

\section{Results and discussion}

Linear isotherms were obtained for the initial very low concentration range. Linear distribution coefficients ( $K_{d}$ values) were obtained from the initial slope (first two data points) of the linear graph of $c_{s}$ against $c_{\text {eq }}$.

$c_{s}=K_{d} c_{\mathrm{eq}}$

$c_{s} \ldots$ sorbed amount of substance on the solid surface $\left(\mathrm{mg} \mathrm{kg}^{-1}\right)$

$c_{\text {eq }} \ldots$ solution equilibrium concentration $\left(\mathrm{mg} \mathrm{L}^{-1}\right)$

$K_{d} \ldots$ sorption (distribution) coefficient $\left[\left(\mathrm{mg} \mathrm{kg}^{-1}\right) /\right.$ $\left.\left(\mathrm{mg} \mathrm{L}^{-1}\right)\right]$

$K_{\mathrm{oc}}=K_{d} /\left(f_{\mathrm{oc}}\right)$, with $f_{\mathrm{oc}}=$ fraction of organic carbon

At higher, i.e., more realistic concentrations, or when the concentration spans several orders of magnitude, the Freundlich equation is more suitable for fitting the sorption behavior: sorption isotherms were thus also analyzed using the Freundlich equation and represented in a doublelogarithmic plot:

$c_{s}=K_{f} c_{\mathrm{eq}}^{1 / n}$

in the linearized form: $\log c_{s}=\log K_{f}+1 / n \log c_{e q}$ $K_{f} \ldots$ Freundlich constant $\left[\mathrm{mg}^{1-1 / n} \mathrm{~kg}^{-1} \mathrm{~L}^{1 / n}\right] ;$ more intuitively: $K_{f}=c_{s}$ at $c_{\text {eq }}=1 \mathrm{mg} \mathrm{L}^{-1}$

$1 / n \ldots$ Freundlich exponent (slope of the double-log plot, or deviation from linearity in the linear form)

A typical shape of sorption isotherms is represented in Fig. 1 and discussed below.

\subsection{The influence of $\mathrm{pH}$ on the adsorption of MCPA}

Sorption experiments were performed at $\mathrm{pH}=3$ and at the unadjusted $\mathrm{pH}$ of $\sim 7$. Upon acidification, an increase of sorption was observed; there is a clear shift of the sorption curves to the upper left (compare Fig.1 b with Fig.1 a, for both soils $\mathrm{C}$ and $\mathrm{E}$, respectively). Freundlich parameters $\left(K_{f}\right.$ and $1 / n$ ) and linear distribution coefficients $K_{d}$ as well as $K_{\mathrm{oc}}$ values are presented in Table 2 . The $K_{\mathrm{oc}}$ is the sorption coefficient normalized to the organic carbon content; the values are not significantly different in most cases, except for the measurements at $\mathrm{pH}=3$, where the values are up to one order of magnitude larger.

The lipophilic aromatic part of MCPA is not influenced by the $\mathrm{pH}$, in contrast to the carboxylic group. The $\mathrm{pK}_{a}$ value of MCPA $\left(\mathrm{pK}_{a}=3.07\right)$ implies that the compound exists mainly in the deprotonated anionic form throughout a wide $\mathrm{pH}$ range in natural waters and soil solutions. The results obtained indicated the greatest sorbed amount of MCPA at $\mathrm{pH}=3$ (where $\sim 50 \%$ are present as deprotonated 
Fig. 1 Sorption isotherms of MCPA on soils C vs. E after 3 months of incubation; effect of $\mathrm{pH}=3$ (a) vs. unadjusted and unbuffered $\mathrm{pH}(\mathbf{b}, \sim 7)$; left double logarithmic plot, right linear plot
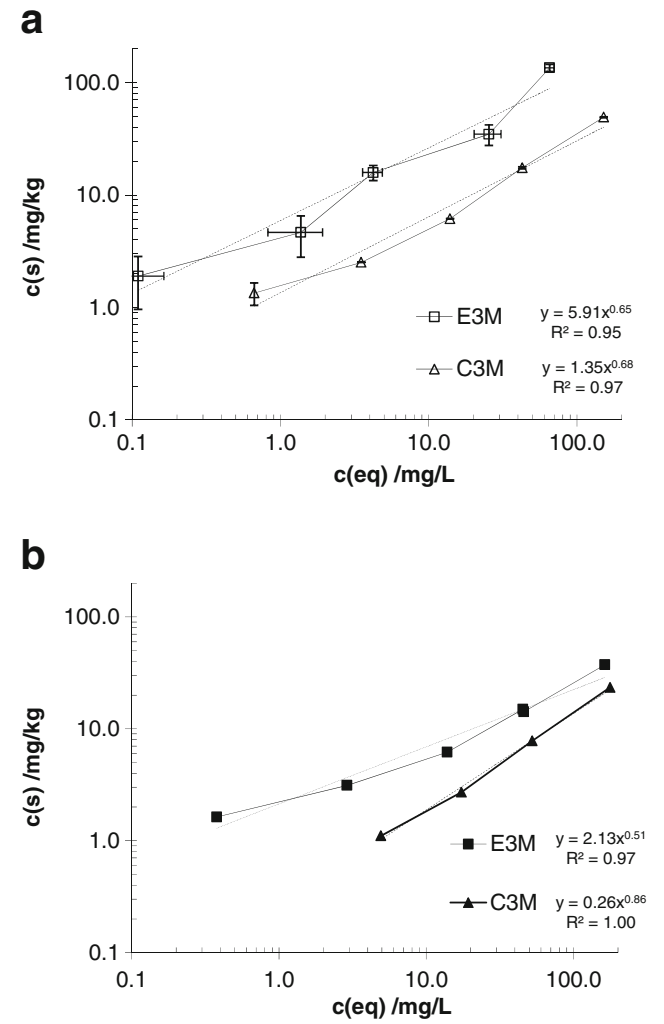
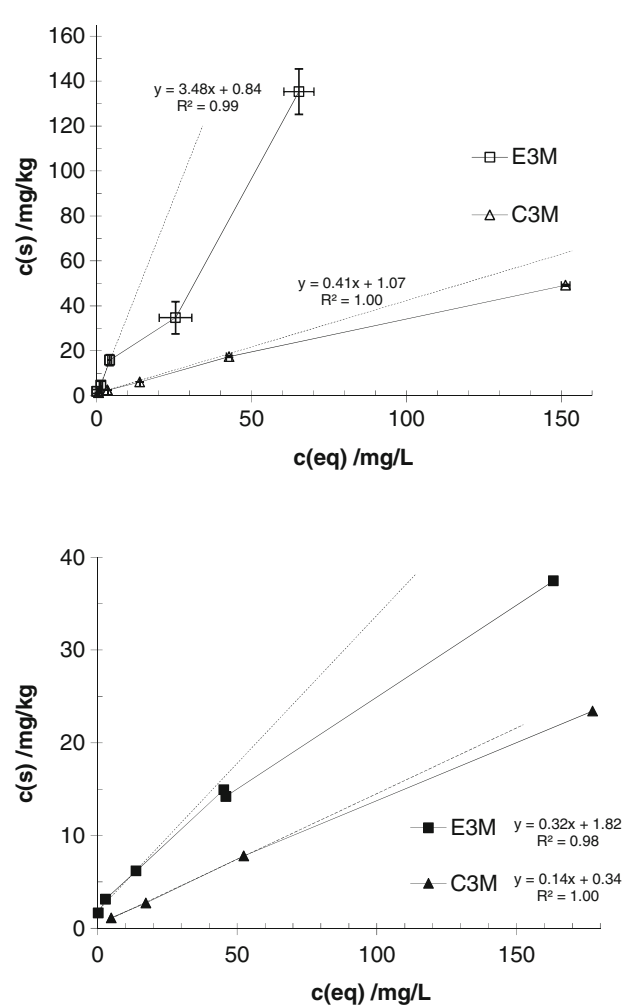

(anionic) and protonated (neutral) species, respectively). Ionic interaction of oppositely charged species is stronger than Van der Waals interactions; this is especially important in the discussion of the present case, considering the $\mathrm{pK}_{a}$ value of MCPA and the point of zero charge (pzc) of many of the soil components, e.g., iron oxides, montmorillonite, and illite: pzc $>8$ (Scheffer and Schachtschabel 2002). At pH values between the $\mathrm{pK}_{a}$ and pzc, the mainly present anionic solution species (deprotonated MCPA in the carboxylate form) strongly interact with positively charged surface sites, whereas charcoal offers mainly uncharged surface sites and preferably sorbs neutral solution species (e.g., the neutral, i.e., protonated MCPA). This trend of increasing sorption of acidic herbicides with decreasing $\mathrm{pH}$, as expected from theory, was observed by many authors like Haberhauer et al. (2001), Paszko (2011), and Hiller et al. (2012); besides, Paszko (2011) distinguished between hydrophobic and hydrophilic sorption of MCPA. The surface charge of the present soils was not determined here but can be expected to be net positive, at $\mathrm{pH}$ values below the pzc of the predominant soil components (e.g., Iglesias et al. 2010).

\subsection{Influence of soil composition and complexity}

With increasing complexity of the soils (compare soils $\mathrm{C}$ vs. $\mathrm{E}$ and $\mathrm{H}$ after 3 months of pre-incubation, Fig. 1a and b, as

Table 2 Freundlich sorption fits

\begin{tabular}{|c|c|c|c|c|c|c|c|c|c|c|c|c|}
\hline \multirow{2}{*}{$\begin{array}{l}\mathrm{pH} \rightarrow \\
\text { Soil }\end{array}$} & \multicolumn{6}{|l|}{7} & \multicolumn{6}{|l|}{3} \\
\hline & $K_{f}$ & $1 / n$ & $R^{2}$ & $K_{d}$ & $f_{\mathrm{oc}}$ & $K_{\mathrm{oc}}$ & $K_{f}$ & $1 / n$ & $R^{2}$ & $K_{d}$ & $f_{\mathrm{oc}}$ & $K_{\mathrm{oc}}$ \\
\hline $\mathrm{C} 3 \mathrm{M}$ & 0.26 & 0.86 & 1.00 & 0.14 & 0.016 & 8.8 & 1.35 & 0.68 & 0.97 & 0.41 & 0.016 & 26 \\
\hline $\mathrm{C} 12 \mathrm{M}$ & & & & & 0.015 & & & & & & 0.015 & \\
\hline $\mathrm{C} 18 \mathrm{M}$ & 0.16 & 0.97 & 0.98 & & 0.013 & & & & & & 0.013 & \\
\hline E3M & 2.13 & 0.51 & 0.97 & 0.32 & 0.030 & 11 & 5.91 & 0.65 & 0.95 & 3.48 & 0.030 & 116 \\
\hline E12M & & & & & 0.028 & & & & & & 0.028 & \\
\hline E18M & 0.35 & 0.85 & 0.99 & & 0.026 & & & & & & 0.026 & \\
\hline $\mathrm{H} 3 \mathrm{M}$ & 2.06 & 0.41 & 0.88 & 0.18 & 0.031 & 5.8 & & & & & 0.031 & \\
\hline $\mathrm{H} 12 \mathrm{M}$ & 0.54 & 0.81 & 1.00 & 0.41 & 0.028 & 15 & 7.9 & 0.68 & 0.99 & & 0.028 & \\
\hline H18M & 0.28 & 0.96 & 0.97 & 0.51 & & & 10.7 & 0.57 & 0.99 & & & \\
\hline
\end{tabular}

Explanations cf. Eqs. 1 and 2; soil codes, $C 3 M$ soil C, 3 months of pre-incubation, etc.; $f_{\text {oc }}$ values calculated from Pronk et al. (2012)

$K_{f}$ Freundlich constant, $1 / n$ exponent, $R^{2}$ coefficient of determination, $K_{d}$ distribution coefficient (linear fit), $K_{o c} K_{d} / f_{\mathrm{oc}}$ 
Fig. 2 Sorption isotherms of MCPA on soil $\mathrm{H}$ after different incubation periods; unadjusted and unbuffered $\mathrm{pH}(\sim 7)$

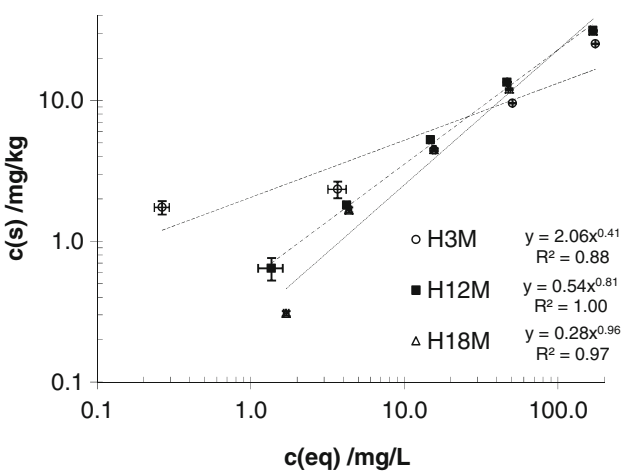

well as Table 2), $K_{f}$ values increased and the linearity decreased, as shown by the $1 / n$ values falling below 0.5 . However, in this case, the $K_{d}$ values did not show a clear trend; the discrepancy between $K_{f}$ and $K_{d}$ values was also discussed by Karnjanapiboonwong et al. (2010). The charcoal content was expected to play a crucial role; there is a slight indication of its influence at both $\mathrm{pH}$ values in Fig. 1 (shift to the upper left, comparing soil C vs. E). The measured BET values are not that high (cf. new data in Table 1), so its influence is not expected to overrule any other contributions of other components. As a consequence, $K_{\mathrm{oc}}$ data did not show a clear trend, except for the drastically increased values at $\mathrm{pH}=3$.

3.3 The influence of biological aging of artificial soils on the sorption of MCPA

Typical sorption isotherms showed a shape like the one depicted in Fig. 2; additional information is given in Table 2. The obtained Freundlich and linear sorption fits are summarized for both $\mathrm{pH}$ values; for explanations cf. Eq. 1 and thereafter. The youngest artificial soil exhibits significant sorption at lowest concentrations; the most prominent difference seems to be a change in sorption characteristics upon aging.

Although the fit of the Freundlich isotherm is not always perfect - especially for soil $\mathrm{H}$ (3 months) - it still seems to be the most reasonable model, as all other sorption theories give worse fits (e.g., Langmuir); the linear sorption model is applicable only at low concentrations.

$K_{f}$ decreases with increased soil aging, with a concomitant increase in the Freundlich exponent $1 / n$, whereas, according to the linear sorption model, the sorption capacity at low concentrations increases (shown by the increasing $K_{d}$ value), with a substantial decrease at higher concentrations. Upon acidification, sorption capacity increases as well: both $K_{f}$ and $K_{d}$ values increase compared to their values at $\mathrm{pH}=7$, and at the same time the $1 / n$ exponent does not show a clear trend.

The results of $\mathrm{N}_{2}$-BET measurements of each component of the soils are given in Table 1. It is obvious that the sum of the components would give a much larger specific surface area for sorption reactions than the incubated artificial soils (compare the larger values of SSA of $\mathrm{MO}, \mathrm{IL}$, and $\mathrm{CH}$ with the very small one of soils $\mathrm{C}, \mathrm{E}$, or $\mathrm{H}$ ). The reduction of the surface area after incubation of the components might be due to interactions of reactive surface and therefore a blocking of reactive sites. Incubation of the artificial soils further reduced the reactivity of the surfaces for sorption with time, probably due to the interaction of the components and their associations, achieving stable micro-aggregates (Six et al. 2004). These micro-aggregates are the basis for the formation of macro-aggregates due to exudates of microorganisms like fungal hyphae or bacteria.

3.4 Measurement of sorption by FTIR (detection of surface species)

FTIR spectra of MCPA, soil $\mathrm{H}$ after 3- and 18-month incubation is shown in Fig. 3, along with the soils plus sorbed MCPA after a simulated sorption experiment: in the latter case, soil was impregnated with a solution of MCPA; the solution was not removed but evaporated. Subsequently, a $\mathrm{KBr}$ pellet with highly MCPA loaded soil sample was prepared. Nevertheless, the concentration was probably below the limit of detection to show any trace of residual or sorbed MCPA on the soil. In contrast to Pusino et al. (1995), the adsorbed herbicide could not be detected with FTIR. Yet, the most prominent features of the spectra of both pure MCPA and soils can be distinguished, i.e., the bands of carboxylic

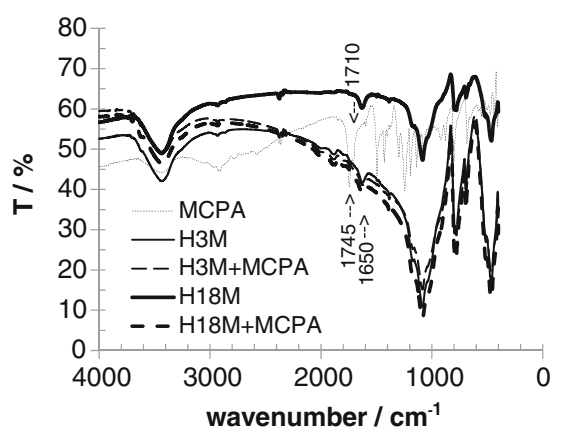

Fig. 3 FTIR measurements of MCPA (dashed thin line) and soils H in different aging states and adsorbate systems 
and carbonyl groups are located around $1,745 \mathrm{~cm}^{-1}$ (MCPA dimer) and $1,710 \mathrm{~cm}^{-1}$ (monomer), and $1,650 \mathrm{~cm}^{-1}$ in soils.

\section{Conclusions}

Aging of artificial soils due to microbial activity results in varying sorption isotherms for MCPA. Older soils (with a longer pre-incubation time) show lower $K_{f}$ and larger $1 / n$ values closer to 1 (increased slope in the double-log plot). The Freundlich equation (monolayer sorption on heterogeneous surfaces) is sufficient to explain many of the sorption curves, with substantial deviations for the younger artificial soils (3 months of pre-incubation).

Regarding the influence of aging, the following conclusions can be drawn: in our experiments, young soils exhibit stronger sorption at lower concentrations, with a decreasing $K_{f}$ and increasing $K_{d}$ values compared to aged soils. Upon aging, the amount of sorbed species per unit surface area is more concentration-dependent. Thus, aging of the organic carbon influences the sorption behavior of the soils more than the organic carbon content itself. Yet, a correlation with organic carbon content is expected but cannot be derived from the present data. Further examination of the behavior of the aged soils and more data points regarding the evolution of the organic carbon content, e.g., monitoring SOM quality, would be required.

Some of the presented observations (e.g., increase of sorption upon acidification and a change of sorption characteristics with increased aging) are known from literature on real soils, but now these concepts were shown to be equally well applicable to artificial soils.

Using FTIR (KBr pellets, transmission mode), the concentration of sorbed species on the solid surface is below the limit of detection under the given circumstances.

Acknowledgments This work was financed by a project (P20893N19) of the Austrian Science Foundation (Fonds zur Förderung der Wissenschaftlichen Forschung, FWF). Alexandra Krombholz is acknowledged for part of the experimental (HPLC) work. Raad Hamid is gratefully acknowledged for performing the $\mathrm{N}_{2}$-BET measurements of the soil minerals.

Open Access This article is distributed under the terms of the Creative Commons Attribution License which permits any use, distribution, and reproduction in any medium, provided the original author(s) and the source are credited.

\section{References}

Addorisio V, Esposito S, Sannino F (2010) Sorption capacity of mesoporous metal oxides for the removal of MCPA from polluted waters. J Agric Food Chem 58:5011-5016

Barrow NJ (1998) The four laws of soil chemistry: the Leeper lecture 1998. Aust J Soil Res 37(5):787-830
Barrow NJ (2008) The description of sorption curves. Eur J Soil Sci 59 (5):900-910

Calvet R (1989) Adsorption of organic chemicals in soils. Environ Health Persp 83:145-177

Cho SY, Park SS, Kim SJ, Kim TY (2006) Adsorption and desorption characteristics of 2-methyl-4-chlorophenoxyacetic acid onto activated carbon. Korean J Chem Eng 23:638-644

Cornell RM, Schwertmann U (1996) The iron oxides. Verlag, Weinheim

Derylo-Marczewska A, Blachnio M, Marczewski WA, Swiatkowski A, Tarasiuk B (2010) Adsorption of selected herbicides from aqueous solutions on activated carbon. J Therm Anal Calorim 101:785-794

Friesl-Hanl W, Haas U, Haberhauer G, Gerzabek MH (2009) Sorption experiments with MCPA and bentazone on several defined surfaces. Poster presentation at the symposium "Advances of Molecular Modeling of Biogeochemical Interfaces - perspectives for Soil Research 2009”, Dornburg/Jena, Germany, Oct. 6-7, 2009

Haberhauer G, Pfeiffer L, Gerzabek MH (2000) Influence of molecular structure on sorption of phenoxyalkanoic herbicides on soil and its particle size fractions. J Agric Food Chem 48:3722-3727

Haberhauer G, Pfeifer L, Gerzabek MH, Kirchmann H, Aquino AJA, Tunega D, Lischka H (2001) Response of sorption processes of MCPA to the amount and origin of organic matter in a long-term field experiment. Eur J Soil Sci 52:279-286

Heister K, Höschen C, Pronk GJ, Mueller CW, Kögel-Knabner I (2012) NanoSIMS as a tool for characterizing soil model compounds and organomineral associations in artificial soils. J Soils Sediments 12:35-47

Hiller E, Tatarkova V, Simonovicova A, Bartal M (2012) Sorption, desorption, and degradation of (4-chloro-2-methylphenoxy)acetic acid in representative soils of the Danubian Lowland, Slovakia. Chemosphere 87:437-444

Iglesias A, López R, Gondar D, Antelo J, Fiol S, Arce F (2010) Adsorption of MCPA on goethite and humic acid-coated goethite. Chemosphere 78(11):1403-1408

Janney DE, Cowley JM, Buseck PR (2000) Transmission electron microscopy of synthetic 2- and 6-line ferrihydrite. Clay Clay Miner 48(1):111-119

Karnjanapiboonwong A, Morse AN, Maul JD, Anderson TA (2010) Sorption of estrogens, triclosan, and caffeine in a sandy loam and a silt loam soil. J Soils Sediments 10:1300-1307

Klepsch S, Aquino AJA, Haas U, Tunega D, Haberhauer G, Gerzabek MH, Lischka H (2011) Sorption of selected aromatic substances -application of kinetic concepts and quantum mechanical modeling. Water Air Soil Poll 215(1-4):449-464

Li H, Sheng G, Teppen BJ, Johnston CT, Boyd SA (2003) Sorption and desorption of pesticides by clay minerals and humic acid-clay complexes. Soil Sci Soc Am J 67:122-131

Paszko T (2011) Adsorption and desorption processes of MCPA in Polish mineral soils. J Environ Sci Heal B 46(7):569-580

Polubesova T, Nir S (1999) Modeling of organic and inorganic cation sorption by illite. Clay Clay Miner 47(3):366-374

Pronk GJ, Heister K, Ding G-C, Smalla K, Kögel-Knabner I (2012) Development of biogeochemical interfaces in an artificial soil incubation experiment; Aggregation and Formation of Organo-Mineral Associations. Geoderma. doi:10.1016/j.geoderma.2012.05.020

Pusino A, Gelsomino A, Gessa C (1995) Adsorption mechanisms of imazamethabenz-methyl on homoionic montmorillonite. Clay Clay Miner 43(3):346-352

Rennert T, Kaufhold S, Brodowski S, Mansfeldt T (2008) Interactions of ferricyanide with humic soils and charred straw. Eur J Soil Sci 59:348-358

Scheffer F, Schachtschabel P (2002) Lehrbuch der bodenkunde, 15th edn. Spektrum Akademischer, Heidelberg, p 593

Sheng G, Johnston CT, Teppen BJ (2001) Potential contributions of smectite clays and organic matter to pesticide retention in soils. $\mathrm{J}$ Agric Food Chem 49:2899-2907 
Six J, Bossuyt H, Degryze S, Denef K (2004) A history of research on the link between (micro)aggregates, soil biota, and soil organic matter dynamics. Soil Tillage Res 79:7-31

Smith AE (1982) Soil persistence studies with ${ }^{14} \mathrm{C}$ MCPA in combination with other herbicides and pesticides. Weed Res 22(3):137-142

Totsche KU, Rennert T, Gerzabek HM, Kögel-Knabner I, Smalla K, Spiteller M, Vogel H-J (2010) Biogeochemical interfaces in soil: the interdisciplinary challenge for soil science. J Plant Nutr Soil Sci 173:88-99
US EPA (1984) Health and environmental effects profile for MCPA and MCPB. U.S. Environmental Protection Agency, Washington, EPA/600/X-84/242 (NTIS PB88162391)

Waldner G, Friesl-Hanl W, Haas U, Haberhauer G, Gerzabek MH (2010) Differences in sorption behavior of MCPA on an artificial soil due to different incubation periods. Poster presentation at the symposium "Advanced Spectroscopic and Microscopic Characterisation Techniques-Tools to Enlighten Biogeochemical Interfaces in Soil", Dornburg/Jena, Germany, Oct. 4-5, 2010 